\section{Sighting of Aglais cashmirensis aesis Fruhstorfer, 1912 (Nymphalidae) from Nagaland, India}

\section{Tshetsholo Naro}

North East Network, P.O. Chizami, Phek District, Nagaland, 797102, India

Email: tshetsholo@gmail.com

The butterflies of Nagaland are not well known. Some early studies of butterflies of the Naga Hills include the work of Tytler (1915). Subsequently, Tytler (1940) also published records of butterflies from neighbouring Burma. Here, I report the presence of Aglais cashmirensis aesis Fruhstorfer from Nagaland, extending its known range.

Since January 2011, I have been observing and photographing butterflies in and around Chizami (25024'0"N \& 94024'0"E; 981m) in the Phek District of Nagaland, $88 \mathrm{~km}$ from the state capital, Kohima. The observations were opportunistic. The butterflies were photographed using digital cameras. The butterflies were identified using Kehimkar (2008) and Evans (1932) and the images were confirmed by Sanjay Sondhi, Titli Trust, Dehradun. Amongst the species

\section{Date of publication (online): 26 April 2012 \\ Date of publication (print): 26 April 2012 \\ ISSN 0974-7907 (online) | 0974-7893 (print) \\ Editor: Peter Smetacek \\ Manuscript details \\ Ms \# 03019 \\ Received 23 November 2011 \\ Final received 24 February 2012 \\ Finally accepted 10 March 2012}

Citation: Naro, T. (2012). Sighting of Aglais cashmirensis aesis Fruhstorfer, 1912 (Nymphalidae) from Nagaland, India. Journal of Threatened Taxa 4(4): 2534-2535.

Copyright: () Tshetsholo Naro 2012. Creative Commons Attribution 3.0 Unported License. JoTT allows unrestricted use of this article in any medium for non-profit purposes, reproduction and distribution by providing adequate credit to the authors and the source of publication.

Acknowledgement: I would like to thank North East Network (NEN) for involving me in the nature conservation education programme. I offer my admiration and gratitude to Payal Bhojwani Molur, Maya Khosla and Rita Banerji for their relentless guidance and mentoring through the nature conservation education programme in Chizami Nagaland, which pulled me into the world of butterflies. Most of all, I am obliged to Sanjay Sondhi who taught me the intricacies of butterfly watching and identification and also helped me in drafting this manuscript.

OPEN ACGESS | FREE DOWNLOAD that were identified was the Indian Tortoiseshell Aglais cashmirensis aesis.

Aglais cashmirensis aesis is the eastern subspecies of Aglais cashmirensis Kollar with a known distribution from Shimla (Himachal Pradesh) eastwards to western Arunachal Pradesh. Aglais cashmirensis cashmirensis is the western subspecies, which is known from Kulu (Himachal Pradesh) west to Pakistan.

Aglais cashimirensis aesis is a resident of Chizami and is well established throughout the area. The butterfly was photographed on 16 June 2011 (Image 1). It is on the wing throughout the year and has been recorded in all months from March to October. It has been noted mainly on exotic garden flowers in open spaces, basking on rocks, the ground, or on roadsides. It can be seen flying close to the ground and is seen mostly on sunny days. Its larval food plant, Urtica species (Nettles) grows abundantly in the area.

In recent literature, Kehimkar (2008) reported the easternmost distribution of Aglais cashmirensis as Sikkim. Haribal (1992) too, reported its presence in Sikkim. Older literature too, including Wynter-Blyth (1957) and Evans (1932), mention the easternmost distribution as Sikkim. More recently, Manari (2010) clarified that the range of Aglais cashmirensis actually extended further eastwards to Arunachal Pradesh and reported its presence in Rupa in western Arunachal Pradesh, noting that the presence of Aglais cashmirensis in that area had already been reported by Betts (1950) but had been overlooked by subsequent authors.

Publications on butterflies by Tytler (1915), whose work covered the Naga Hills and Manipur does not report this species from the area. In their report on the butterflies of the Khasi and Jaintia hills, Parson \& Cantlie (1948) state, "Although there is no reason why this species should not be found on the high plateau, we know of no record".

In more recent butterfly surveys in northeastern India including the South Garo Hills, Meghalaya (Sanjay Sondhi pers. comm. 07 July 2011), Namdapha Tiger Reserve in eastern Arunachal Pradesh (unpublished checklist Sanjay Sondhi) and the Dibang Dihang Biosphere Reserve (Borang 2008) from the higher elevations of central Arunachal Pradesh, there 


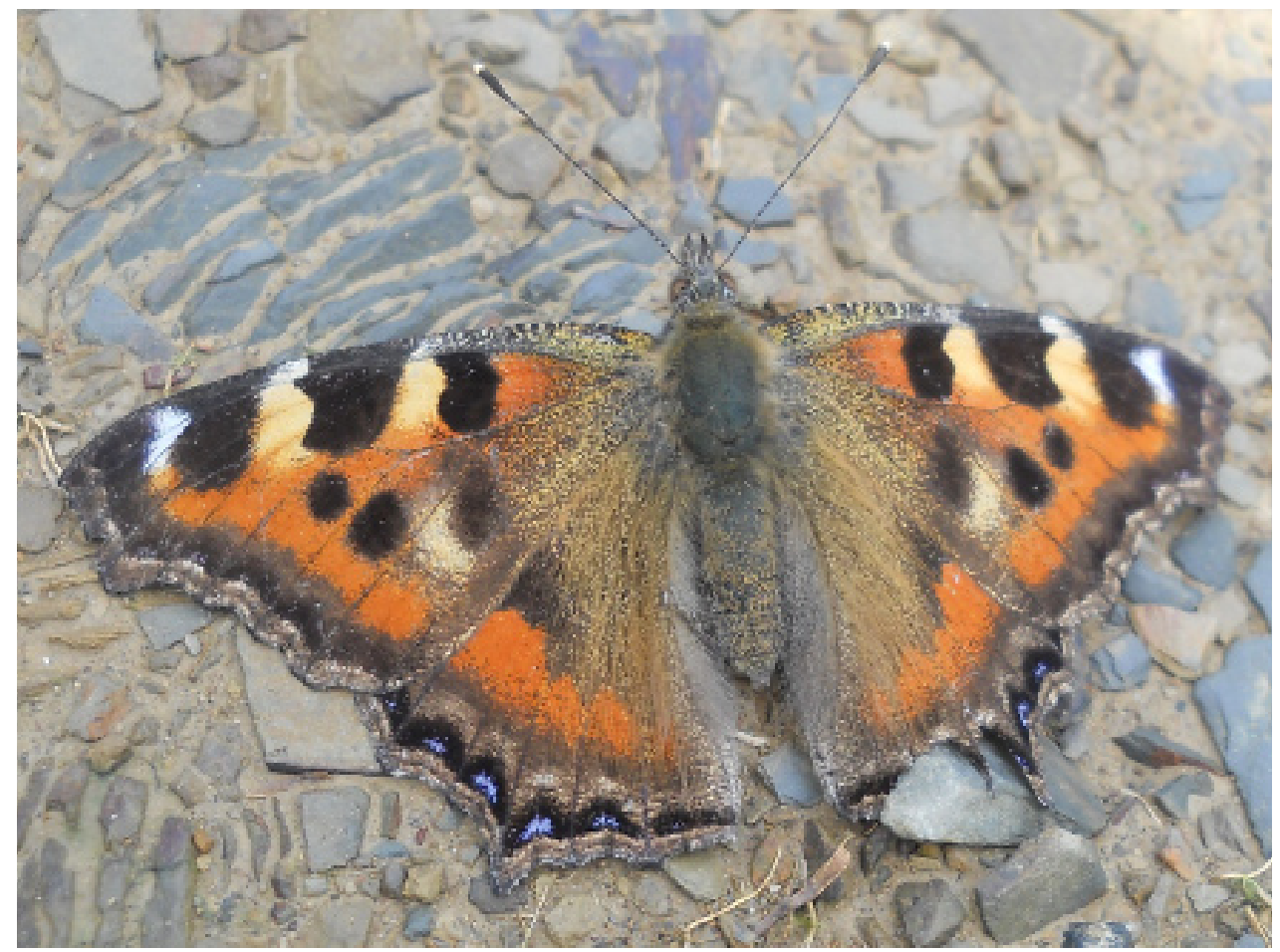

Image 1. Indian Tortoiseshell Aglais cashmirensis aesis photographed on 16 June 2011 at Chizami Village, Nagaland have been no records of Aglais cashmirensis.

Finally, there have been no records of this species from the neighboring countries of Bangladesh (Larsen 2004) and Myanmar (Tytler 1940; Kinyon 2004).

The record of Aglais cashmirensis aesis from Chizami, Phek District, Nagaland extends its known range significantly eastwards from western Arunachal Pradesh. It is, however, surprising that there have been no reported sightings of this butterfly from the area between there and Nagaland, specifically eastern Assam and Arunachal Pradesh.

\section{REFERENCES}

Betts, F.N. (1950). On a collection of butterflies from the Balipara Frontier Tract and the Subansiri area (northern Assam). Journal of the Bombay Natural History Society 49(3): 488-502.

Borang, A., B.B. Bhatt, M. Tamuk, A. Borkotoki \& J. Kalita (2008). Butterflies of Dihang Dibang Biosphere Reserve of Arunachal Pradesh, Eastern Himalayas, India. Bulletin of Arunachal Forest Research 24(1\&2): 41-53.
Evans, W.H. (1932). The Identification of Indian Butterflies2nd Edition. Bombay Natural History Society, Bombay, $\mathrm{x}+454 \mathrm{pp}+32 \mathrm{pl}$.

Manari, G. (2010). On the presence of Aglais cashmirensis Kollar (Nymphalidae) and Heliophorus sena Kollar (Lycaenidae) in Rupa, Arunachal Pradesh, India. Journal of Threatened Taxa 2(9): 1165-1166.

Haribal, M. (1992). The Butterflies of The Sikkim Himalaya and Their Natural History. Sikkim Nature Conservation Foundation, Gangtok, 217pp.

Kehimkar, I. (2008). The Book of Indian Butterflies. Bombay Natural History Society and Oxford University Press, New Delhi, xvi+497pp.

Larsen, T.B. (2004). Butterflies of Bangladesh - An Annotated Checklist. IUCN, Bangladesh, 158pp +8 colour pls.

Tytler, H.C. (1915). Notes on some new and interesting butterflies from Manipur and the Naga Hills-Part II. Journal of the Bombay Natural History Society 23: 502$515+4$ pls.

Tytler, H.C. (1940). Notes on some new and interesting butterflies chiefly from Burma. Journal of the Bombay Natural History Society 42: 109-123.

Wynter-Blyth, M.A. (1957). Butterflies of the Indian Region. Bombay Natural History Society, Bombay, $\mathrm{xx}+523 \mathrm{pp}+72 \mathrm{pl}$. 